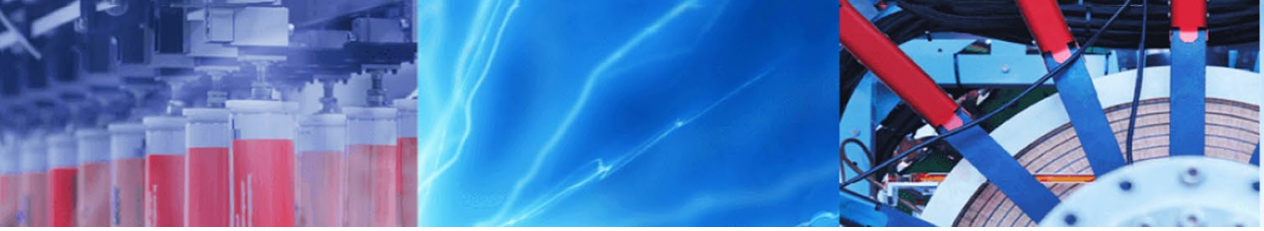

Research Article

\title{
Fuzzy logic model for investigating the effect of steel fibers on mechanical properties of concrete
}

\author{
Fayyaz Rahman ${ }^{1} \cdot$ Muhammad Raheel $^{1}$ (D) Rawid Khan ${ }^{1}$
}

(c) Springer Nature Switzerland AG 2019

\begin{abstract}
This study aimed to use fuzzy logic model to predict various mechanical properties such as compressive strength, flexural strength and post-peak deformation of steel-fiber reinforced concrete. For this purpose, five different dosages of steel fibers $\left(10 \mathrm{~kg} / \mathrm{m}^{3}, 12.5 \mathrm{~kg} / \mathrm{m}^{3}, 15 \mathrm{~kg} / \mathrm{m}^{3}, 17.5 \mathrm{~kg} / \mathrm{m}^{3}\right.$ and $\left.20 \mathrm{~kg} / \mathrm{m}^{3}\right)$ were used in the mix design. A total of 3 specimens (cylinders and beams) were casted for each fiber dosage and experimentally tested. The experimental results were compared with the simulated results obtained from fuzzy model using fuzzy logic toolbox provided in MATLAB ${ }^{\oplus}$. It was found that the addition of steel fibers improved the flexural strength and post-peak deformation capability of test specimens by almost $12 \%$ and $20 \%$ respectively. The compressive strength of specimens also increased by $9.15 \%$, when the amount of steel fibers was increased from 10 to $20 \mathrm{~kg} / \mathrm{m}^{3}$. Overall, the compressive strength reduced with the addition of fibers as compared to specimens with no fibers. Similarly, it was also observed that fuzzy model can predict the study parameters within acceptable accuracy and the percentage difference between the simulated and experimental values was below $7.5 \%$.
\end{abstract}

Keywords Concrete $\cdot$ Steel fibers · Fuzzy logic application $\cdot$ Flexural strength

\section{Introduction}

Concrete is recognized for its widespread use and durability. It has applications in almost every infrastructure like rigid pavements, the structural components of buildings and bridges and even, concrete made pipes which are used for the conveyance of sewage. Concrete is very strong in compression but, in most of the cases, its ability to resist tension and flexural loadings is challenged $[2,3]$. To overcome the weakness of concrete in tension, mildsteel reinforcement is used. However, the trend is now changing and efforts have been made by various researchers like [1-3], by incorporating different types of fibers like steel fibers, glass fibers, polypropylene fibers and their combination, to improve the tensile and flexural strength of concrete.
Efforts have been made to study the impact of steel fibers on the compressive strength of specimens through various studies $[1,4,5]$. For example, the study conducted by Yoo and Yoon [5], showed that the incorporation of steel fibers did not improve the compressive strength of concrete considerably. For example, the compressive strength obtained for control and specimen with a reinforcement ratio of $1.5 \%$ was $201 \mathrm{MPa}$ and $211 \mathrm{MPa}$ respectively. Similarly, Wu et al. [4] also observed that the amount of steel fibers made negligible improvements in the compressive strength of specimens. According to experimental results, the compressive strength only improved by $12 \%$ for a steel fibers dosage of $0.9 \%$. Similar results were reported by Lee et al. [6], in which the incorporation of steel fibers did not improve the compressive strength of concrete specimens considerably.

Muhammad Raheel, mraheel14@gmail.com; Fayyaz Rahman, enginrfayyaz@gmail.com; Rawid Khan, Dr.rawid@uetpeshawar.edu.pk ${ }^{1}$ Department of Civil Engineering, University of Engineering and Technology Peshawar, Peshawar, Pakistan. 
In contrast, it has been observed that the addition of steel fibers has major positive impact on the flexural strength of specimens $[1,2,7,8]$. The experimental program carried-out by Yoo et al. [9], involved testing of full-scale beam specimens. It was observed that the addition of steel fibers enabled the specimens to take more flexural load and ensured high post-peak stiffness. The flexural strength increased by almost $20 \%$ as compared to specimens without steel fibers. During testing of specimen under flexural load, it was observed that the specimen showed a ductile failure mode due to bridging of cracks by steel fibers. Lee et al. [6] made an attempt to study the impact of increasing amounts of steel fibers on the flexural and compressive strength of specimens. The results revealed that the addition of fibers improved the equivalent flexural strength ratio, which is the ratio of first peak strength and energy absorption capacity of specimen. The overall flexure strength improved by about $22 \%$ as compared to specimens without steel fibers.

According to [10] and [11], fuzzy logic is very userfriendly and its rules can be very easily written depending on experience. Fuzzy logic modelling allows us to write the relationship between input(s) and output(s) verbally. In fact, Fuzzy logic can be very useful, if the relationship between the input and output is fuzzy. Various researchers [11-13], have used fuzzy logic and neural networking to predict various properties of concrete like compressive strength, flexural strength and the impact of various types of additives like fly ash and low lime concretes. For example Saridemir Mustafa [12], studied the impact of adding metakaolin on the compressive strength of cement mortars. The results were also simulated on Fuzzy logic and artificial neural networking. It was found that fuzzy logic can successfully predict the compressive strength of test specimens. Statistical analysis of data gave a root mean square (RMS) value of 0.28 . Artificial neural networking also produced acceptable results with RMS value of 1.79 . The obtained slope and intercept values for fuzzy model were 0.9764 and 0.5842 respectively. Thamma and Barai [14], used gene expression programming to simulate the effect of Blaine and Alkalis on the compressive strength of cement mortar. It was found that gene expression programming can successfully predict the compressive strength of cement mortar with RMS value of 1.4956. Similarly, another study was conducted by Bekir and Mustafa [13], which involved predicting the compressive strength of concrete using fuzzy logic and artificial neural networking. The obtained RMS value was 2.02 and the linear fit of equation give a slope and intercept value equal to 0.9824 and 0.6354 respectively. According to them, the statistical analysis of results concluded that the results produced by both models were not only satisfactory, but also reliable.
As evident from literature review, different researchers used fuzzy logic modelling for predicting mechanical properties of concrete like compressive and flexural strength by adding different types of admixtures/fibers. In this study, fuzzy logic model was used to predict post-peak deformation capability of test specimens in addition to other mechanical properties such as compressive and flexural strength. In previous studies, fuzzy model was mostly based on experimental data of other researchers. This study involved casting and testing of specimens followed by their modelling in fuzzy logic.

The objective of this experimental study is to evaluate the impact of locally available steel fibers on the mechanical properties of concrete such as compressive strength, flexural strength and post-peak deformation. For this purpose, five different amounts of steel fibers $10 \mathrm{~kg} / \mathrm{m}^{3}, 12.5 \mathrm{~kg} / \mathrm{m}^{3}$, $15 \mathrm{~kg} / \mathrm{m}^{3}, 17.5 \mathrm{~kg} / \mathrm{m}^{3}$ and $20 \mathrm{~kg} / \mathrm{m}^{3}$ were used, respectively. The amount of steel fibers added is also expressed in terms volume of concrete which are $0.13 \%, 0.16 \%, 0.24 \%, 0.42 \%$ and $0.84 \%$, respectively. The impact of steel fibers on the afore-mentioned mechanical properties is also predicted by fuzzy logic algorithm. Finally, the experimental results were compared with the simulated data.

\section{Experimental program}

In this study, ordinary Portland cement conforming to ASTM C150 [15], fine and coarse aggregates conforming to ASTM C33 [16], were utilized. Similarly, locally available binding wire, which is made up of mild steel and commonly used for binding reinforcement in Reinforced Concrete buildings, was used in the mix. The length and diameter of steel fibers was $30 \mathrm{~mm}$ and $0.2 \mathrm{~mm}$ respectively.

Several problems like clumping of fibers and their non-uniform distribution are associated, if proper care is not taken during mixing of materials as reported by $[17,18]$. For this reason, first, small amounts of fibers were added to coarse aggregate and mixed until the desired quantity was added. The process was followed with the addition of fine aggregate, cement and water. The gradation curves of fine and coarse aggregates is shown in Fig. 2. It is important to note that proper mixing was carried-out following the addition of each material. The mix design adopted for this study is shown in Table 1. Two types of specimens were casted i.e. cylinders and beams as shown in Fig. 1. The cylinders had

Table 1 Mix proportions

\begin{tabular}{lllll}
\hline W/C ratio & \multicolumn{4}{l}{ Unit weight $\left(\mathrm{kg} / \mathrm{m}^{3}\right)$} \\
\cline { 2 - 5 } & Water & Cement & Fine aggregate & Coarse aggregate \\
\hline 0.40 & 180 & 450 & 900 & 1800 \\
\hline
\end{tabular}


Fig. 1 Test specimens
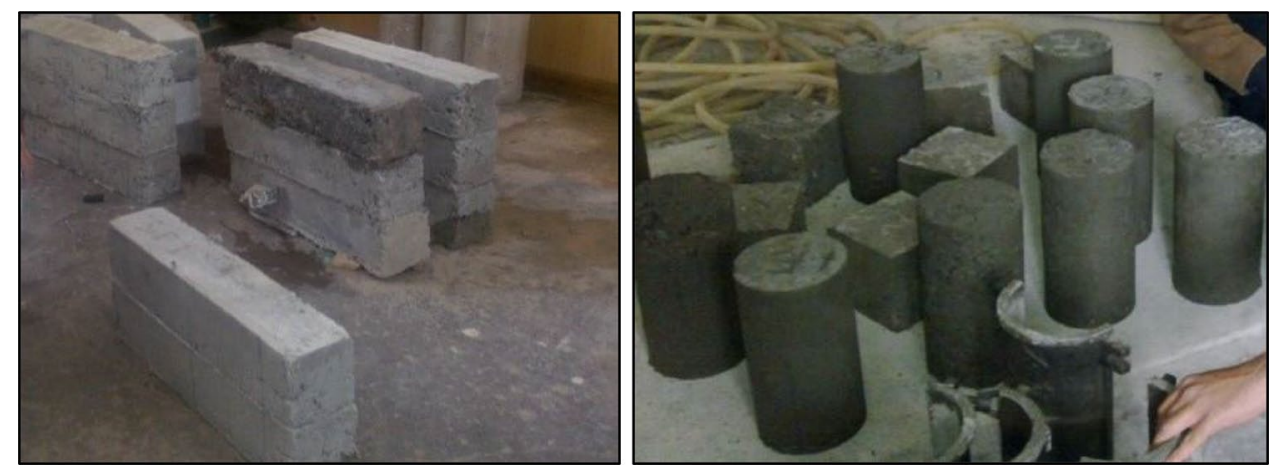

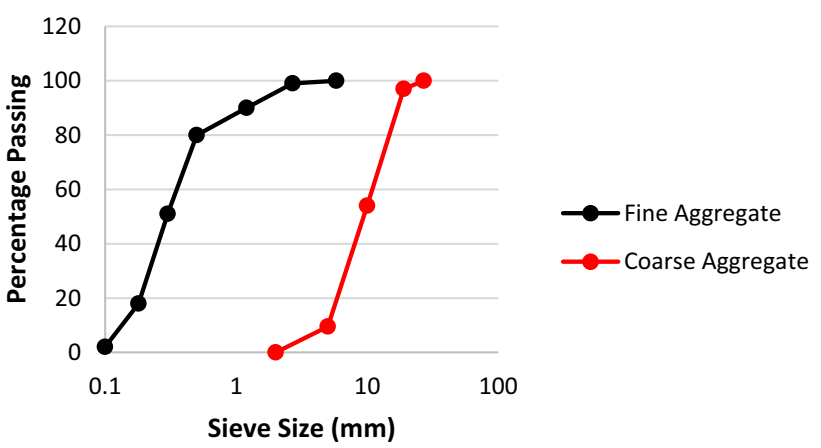

Fig. 2 Sieve analysis of fine and coarse aggregates

length to diameter ratio equal to $2(305 \mathrm{~mm} \times 152 \mathrm{~mm})$ as stated in ASTM C39 [19]. Similarly, the flexural strength was evaluated by casting beams having dimension $457 \mathrm{~mm} \times 100 \mathrm{~mm} \times 100 \mathrm{~mm}$. Both beams and cylinders were casted for five different amounts of steel fibers designated as SF10, SF12.5, SF15, SF17.5, SF20, where SF stands for steel fibers respectively. A total of 15 beams and cylinders were casted ( 3 for each amount of steel fibers). The reported compressive and flexural strength values represent the average of 3 specimens being casted for each amount of fibers (SF10, SF12.5, SF15, SF17.5, SF20).

The compressive strength was determined with the help of Universal Testing Machine. Strain-gauges were wrapped around the specimens to record the load-deformation history of each specimen. Similarly, the flexural testing of beams was carried-out by Center Point Loading Method as specified by ASTM C293 [20]. According to this specification, the flexural strength of test specimen is given by:

Flexure strength $=3 \mathrm{PL} / 2 \mathrm{BH} 2$

where $P=$ load at failure, $L=$ effective span of beam, $B=$ width of beam, $\mathrm{H}=$ depth of beam.
It must be noted that for each amount of steel fibers, the average of three specimens was reported as the final result.

\section{Fuzzy logic modelling}

In this research study, fuzzy logic-based model was used to simulate the effect of amount of steel fibers on the mechanical properties of concrete i.e. compressive strength, flexural strength and post-peak deformation of test samples. Fuzzy rules were written for this purpose in fuzzy logic toolbox present in MATLAB ${ }^{\circledR}$. Fuzzy logic deals with real world problems in a natural way, where the absence of sharply defined criteria becomes the cause of imprecision. It is very helpful in problems where linguistic uncertainties can play a role in the control mechanism of problem/study concerned [12]. Fuzzy logic was selected based on its ease to develop its rules, simulate the results in a short time and requires a smaller number of experimental data to develop a representative model of study variable [21]. Fuzzy logic has widely been used for modelling various engineering problems like mechanical properties of solder alloys, mechanical properties of concrete, traffic volumes and rainfall prediction models [11], [22].

Figure 3 depicts the workflow of proposed model. The model takes-in the amount of steel fibers as input, which is transformed into fuzzy plane. Base rules are written which determines the study's outputs based on centroid method, and Mamdani method is used for defuzzification.

\subsection{Membership functions}

The numerical model had one input 'amount of steel fibers' and three outputs 'compressive strength, flexural strength and post-peak deformation'. The membership functions (MFs) for both the input and output are shown in Figs. 5 and 6. According to [23], the construction of membership functions requires experience to place the base values in 
Fig. 3 Workflow of fuzzy logicbased simulation

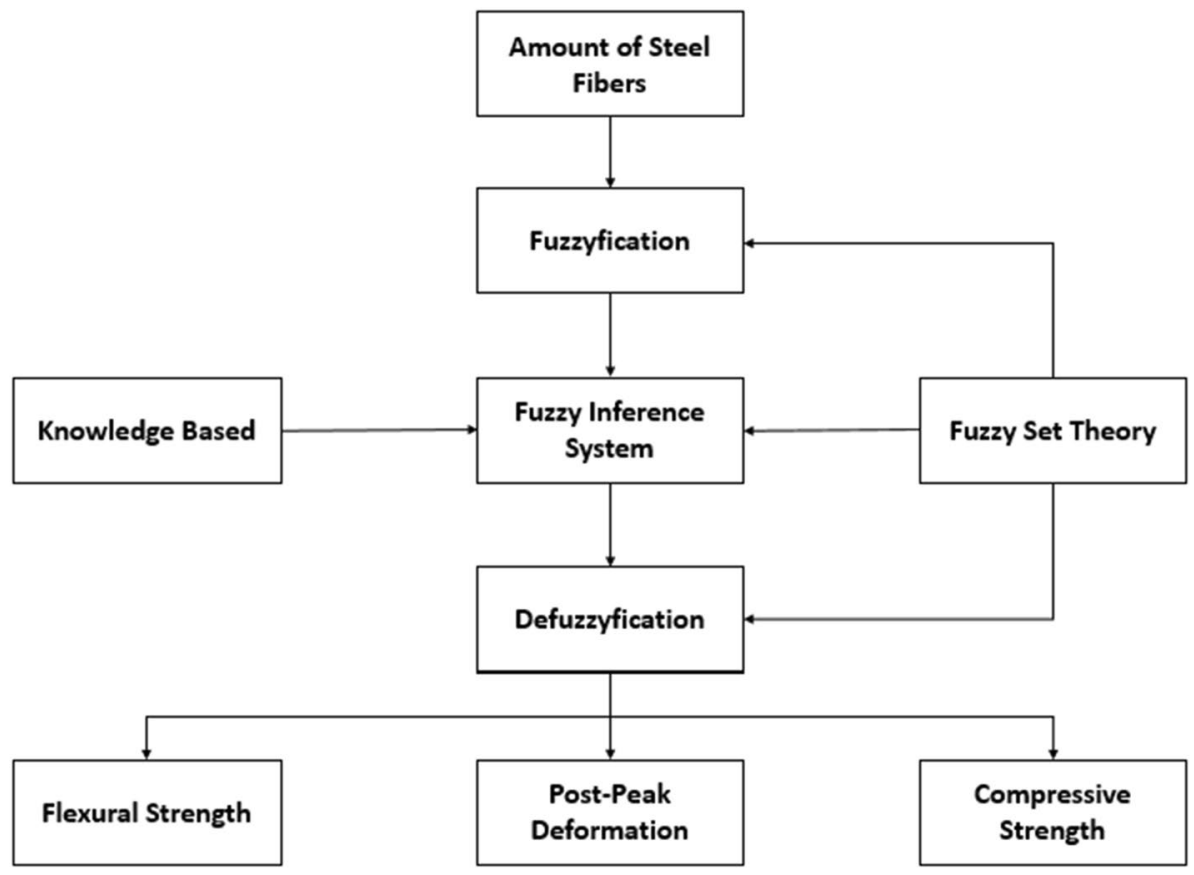

shown in Fig. 4 and Eq. 2 [24]. Therefore, this study used the same for both input and output parameters.

$T_{n} F(x ; a, m, b)= \begin{cases}0, & x \leq a \\ \frac{x-a}{m-a}, & a<x \leq m \\ \frac{b-x}{b-m}, & m<x<b \\ 0, & x \geq b\end{cases}$

\subsection{Fuzzy sets}

During the model development, the input parameter 'amount of steel fibers' was divided into eleven fuzzy sets. These are VVL (very very low), VL (very low), L (low), VVM (very very moderate), VM (very moderate),

give better results and, are most widely used. Triangular MFs can be mathematically and graphically interpreted as

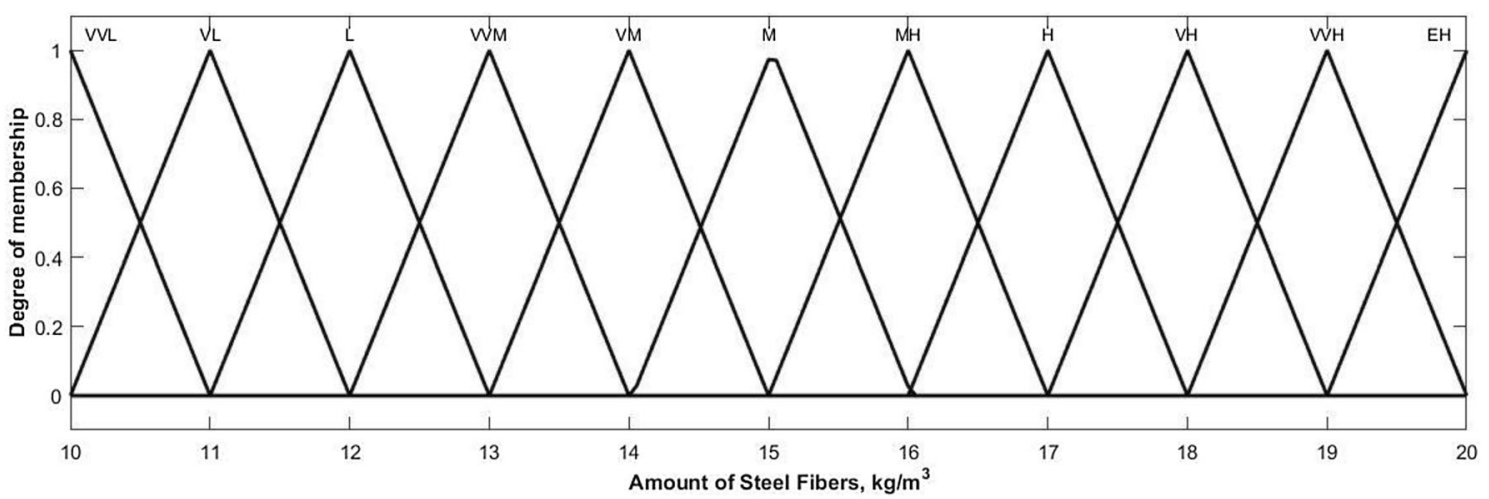

Fig. 5 Membership function for input 

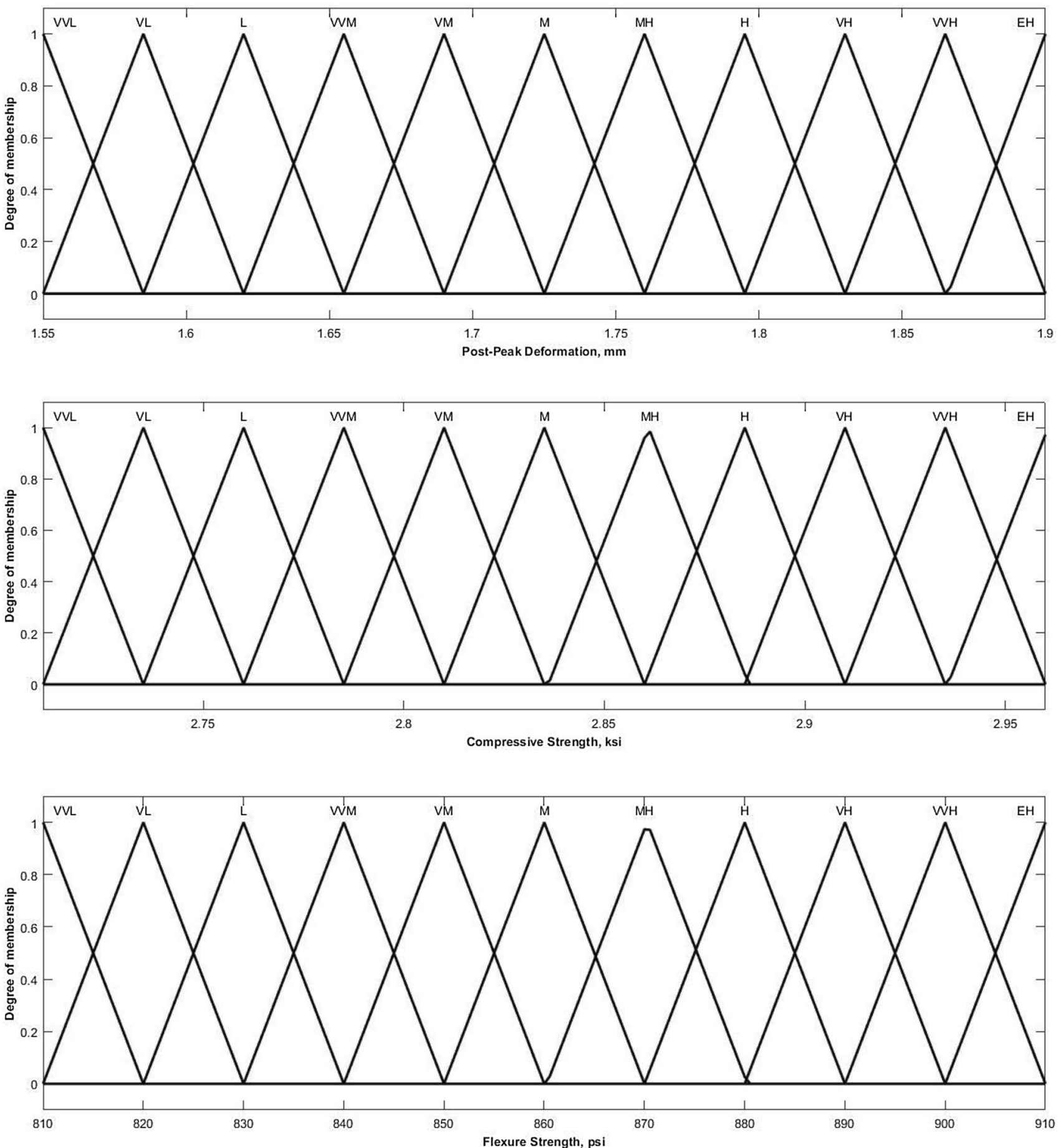

Fig. 6 Membership function for outputs

$\mathrm{M}$ (moderate), $\mathrm{MH}$ (moderately high), $\mathrm{H}$ (high), $\mathrm{VH}$ (very high), VVH (very very high), EH (extremely high). In the same manner, the output parameters 'compressive strength, flexural strength and post-peak deformation' were divided into eleven fuzzy sets such as VVL (very very low), VL (very low), L (low), VVM (very very moderate), VM (very moderate), $\mathrm{M}$ (moderate), $\mathrm{MH}$ (moderately high), $\mathrm{H}$ (high), VH (very high), VVH (very very high), EH (extremely high). 
Table 2 Fuzzy rule base for the input and outputs

\begin{tabular}{lllll}
\hline Rules & Input & Output & & \\
\cline { 3 - 5 } & $\begin{array}{l}\text { Amount of } \\
\text { steel fibers }\end{array}$ & $\begin{array}{l}\text { Flexural } \\
\text { strength }\end{array}$ & $\begin{array}{l}\text { Post-peak } \\
\text { deformation }\end{array}$ & $\begin{array}{l}\text { Com- } \\
\text { pressive } \\
\text { strength }\end{array}$ \\
\hline R1 & VVL & VVL & VVL & VVL \\
R2 & VL & VL & VL & VL \\
R3 & L & L & L & L \\
R4 & VVM & VVM & VVM & VVM \\
R5 & VM & VM & VM & VM \\
R6 & M & M & M & M \\
R7 & MH & MH & MH & MH \\
R8 & H & H & H & H \\
R9 & VH & VH & VH & VH \\
R10 & VVH & VVH & VVH & VVH \\
R11 & EH & EH & EH & EH \\
\hline
\end{tabular}

\subsection{Fuzzy rule base}

According to [25], fuzzy rule base is a set of verbal description which has a general form of "IF VA THEN VB", where VA and $V B$ are propositions containing linguistic variables. In order to simulate the impact of amount of steel fibers on the mechanical properties of concrete, the following fuzzy rule base for the proposed fuzzy sets were developed as shown in Table 2.

\section{Results}

Figure 7 shows the impact of amount of steel fibers on the post-peak deformation of test specimens. It can be observed from the figure that the deformation capacity of specimens increases with the amount of steel fibers. The deformation capacity is increased by almost $20 \%$ when the volume of steel fibers is increased from 0.13 to $0.84 \%$ $\left(10-20 \mathrm{~kg} / \mathrm{m}^{3}\right)$.

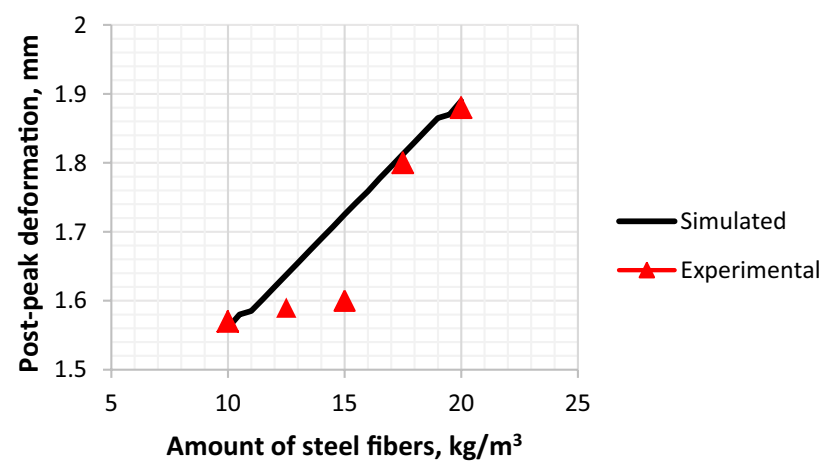

Fig. 7 Effect of steel fibers on post-peak deformation of specimens

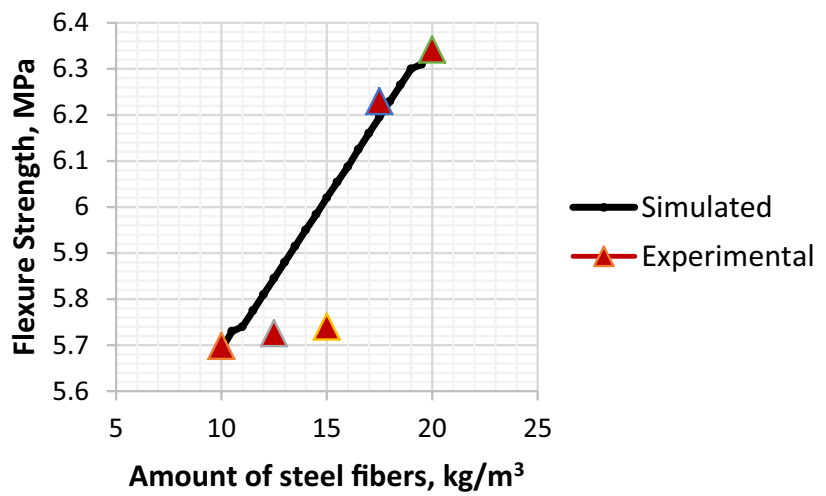

Fig. 8 Effect of steel fibers on flexural strength of specimens

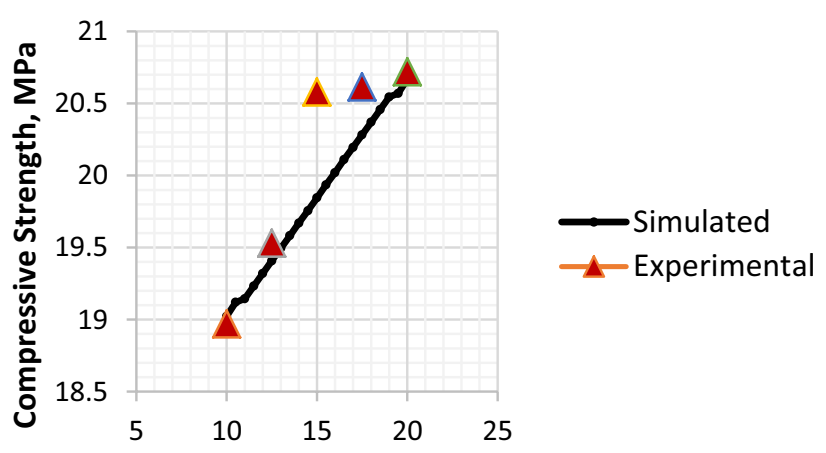

Amount of steel fibers, $\mathrm{kg} / \mathrm{m}^{3}$

Fig. 9 Effect of steel fibers on compressive strength of specimens

Similarly, the simulation shows that the amount of steel fibers improved the flexural capacity of test specimens as depicted in Fig. 7. By comparing specimen SF10 and SF20, it is observed that the flexural strength is increased by almost $12 \%$ (Fig. 8 ).

According to fuzzy logic predicted values of compressive strength for SF specimens, shown in Fig. 9, the compressive strength of specimens increased with the addition of steel fibers. When comparing SF specimens, SF20 had $9.15 \%$ higher compressive strength as compared to SF10. However, the experimental results showed that, the addition of steel fibers reduced the compressive strength of test specimens by almost $31 \%$, as compared to specimens without steel fibers (control group).

\section{Discussions}

The experimental study revealed that the addition of steel fibers improved the post-peak deformation capacity of test specimens by taking load even after yielding. This is due to the fact that steel fibers control the propagation of micro-cracks, helps the specimens to 
Table 3 Comparison of results

\begin{tabular}{|c|c|c|c|c|c|c|}
\hline \multirow[t]{2}{*}{ Specimen type } & \multicolumn{3}{|c|}{ Experimental results } & \multicolumn{3}{|l|}{ Simulated results } \\
\hline & $\begin{array}{l}\text { Flexural strength } \\
\text { (MPa) }\end{array}$ & $\begin{array}{l}\text { Post-peak deforma- } \\
\text { tion }(\mathrm{mm})\end{array}$ & $\begin{array}{l}\text { Compressive } \\
\text { Strength (MPa) }\end{array}$ & $\begin{array}{l}\text { Flexural strength } \\
(\mathrm{MPa})\end{array}$ & $\begin{array}{l}\text { Post-peak deforma- } \\
\text { tion }(\mathrm{mm})\end{array}$ & $\begin{array}{l}\text { Compressive } \\
\text { strength (MPa) }\end{array}$ \\
\hline CG & 7.20 & 0.33 & 28.00 & - & - & - \\
\hline SF10 & 5.69 & 1.57 & 18.97 & 5.69 & 1.56 & 19.04 \\
\hline SF12.5 & 5.73 & 1.59 & 19.53 & 5.73 & 1.64 & 19.39 \\
\hline SF15 & 5.74 & 1.60 & 20.58 & 5.74 & 1.725 & 19.88 \\
\hline SF17.5 & 6.23 & 1.80 & 20.62 & 6.23 & 1.81 & 20.30 \\
\hline SF20 & 6.34 & 1.88 & 20.72 & 6.34 & 1.89 & 20.65 \\
\hline
\end{tabular}

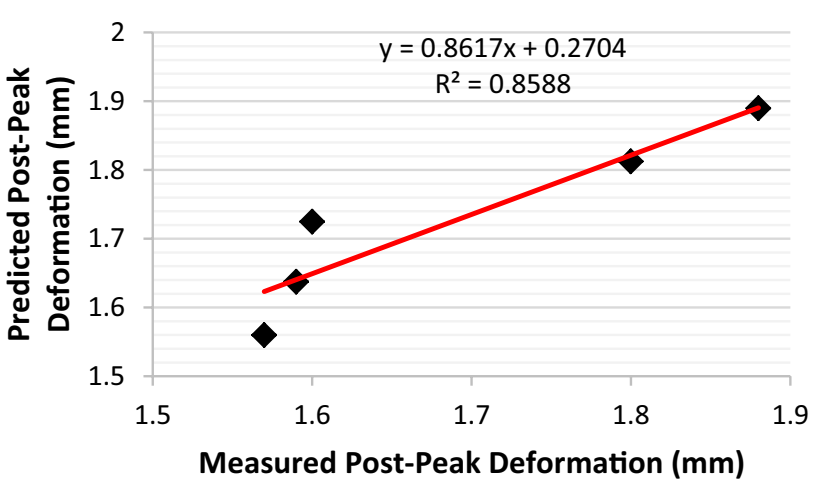

Fig. 10 Correlation of measured and predicted deformation

take load even after yielding and ensures ductile failure of test specimens. Similar results were reported by [1, 26]. In their experiments, it was observed that the control specimens showed brittle failure while in steel fiber specimens, debonding of steel fibers from concrete matrix occurred very slowly and the failure of specimen was not sudden. According to their conclusions, the steel fibers act as anchors which slowed down the propagation of cracks and thus, ensured a ductile failure of specimen. The experimental results also support the simulation results as shown in Table 3 and gives a good fit with the simulation results as depicted in Fig. 10.

The flexure strength of specimens also increased with the addition of steel fibers. The reason being, perfect bonding between fibers and surrounding concrete matrix ensures efficient stress transfer and bridges the microcracks in tension region of flexural members thereby, increasing its capacity in flexural loading. It was also revealed that the SF specimens gives sufficient warning before failure (by undergoing large amount of deformation before failure). The experimental results are also in good agreement with the simulation results as shown in Table 3 (Fig. 11).

In contrast to flexure strength and post-peak deformation results of specimens, the addition of steel fibers

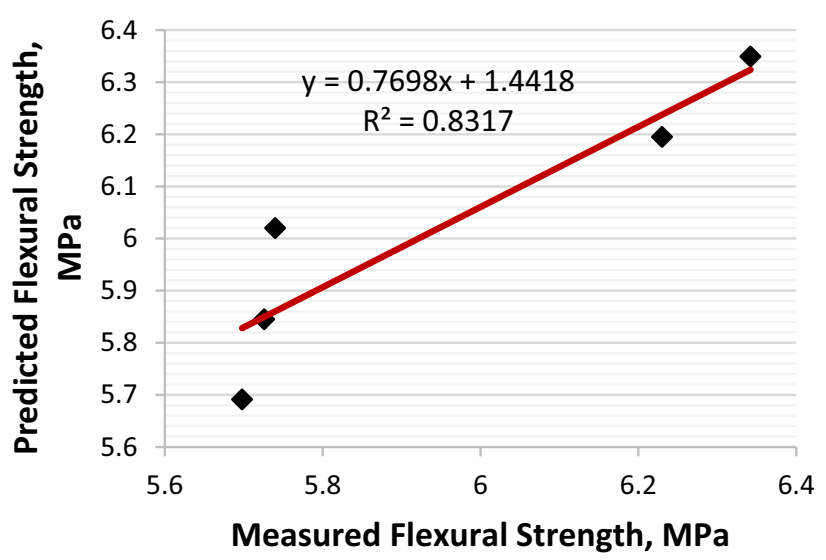

Fig. 11 Correlation of measured and predicted flexural strength

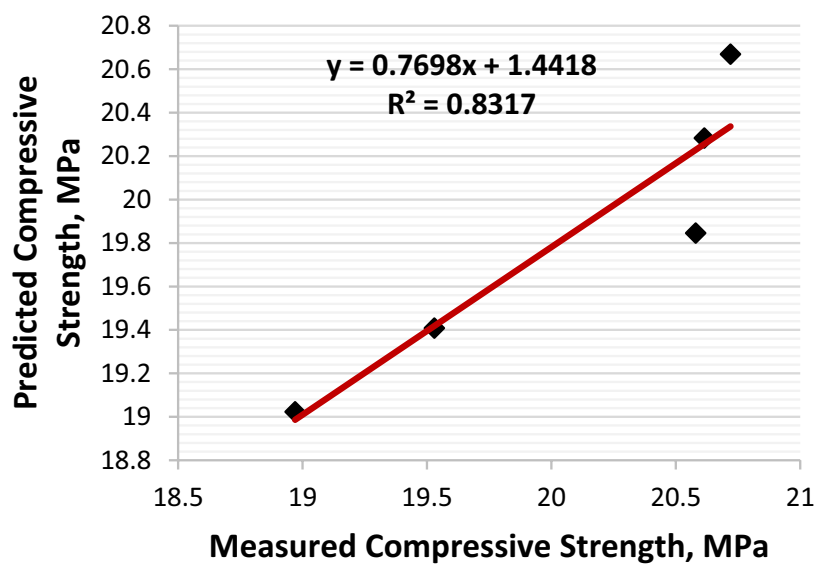

Fig. 12 Correlation of measured and predicted compressive strength

reduced the compressive strength of concrete specimens as compared to control group specimens. However, when the compressive strength results of SF specimens are compared, it is found that SF20 specimens has higher compressive strength as compared to other SF specimens as shown in Fig. 12. Similar results are reported by 
Table 4 Percentage difference between experimental and simulation results

\begin{tabular}{llll}
\hline Specimen type & $\begin{array}{l}\text { Flexural } \\
\text { strength (\%) }\end{array}$ & $\begin{array}{l}\text { Post-peak defor- } \\
\text { mation (\%) }\end{array}$ & $\begin{array}{l}\text { Compressive } \\
\text { strength (\%) }\end{array}$ \\
\hline SF10 & 0.12 & 0.64 & 0.28 \\
SF12.5 & 2.03 & 3.05 & 0.72 \\
SF15 & 4.65 & 7.25 & 3.57 \\
SF17.5 & 0.56 & 0.55 & 1.53 \\
SF20 & 0.11 & 0.56 & 0.25 \\
\hline
\end{tabular}

Falliano et al. [3], in which three different dosages of steel fibers $0.5 \%, 2 \%$ and $5 \%$ were incorporated. A higher compressive strength was observed for the mix having $5 \%$ steel fibers.

Table 4 depicts the percentage difference between the simulated and experimental results. It is evident that the percentage difference between the simulated and experimental values is less than $7.5 \%$, and most of the values are below $1 \%$. These results are in accordance with Tanyildizi [23]. According to Tanyildizi, if the percentage difference between simulated and experimental results is less than $10 \%$, then the fuzzy model is reliable, and can be used to predict other values. Similarly, the correlation factor 'R2' was also determined between the measured and predicted values. The obtained $\mathrm{R} 2$ value for deformation capacity, flexural and compressive strength is $0.86,0.83$ and 0.85 respectively, which, again, shows that fuzzy model predicted the results close to experimental values. Bekir and Mustafa [13] obtained an R2 value of 0.99 using fuzzy logic modelling of compressive strength of concrete. Similarly, Mustafa Saridemir [12] obtained an R2 value of 0.96 for fuzzy logic modelling of flexural strength of concrete specimens having steel fibers. The reason for their higher $\mathrm{R} 2$ value is due to large number of data points being experimented and simulated, which allowed better training of fuzzy model for that particular study.

\section{Conclusions}

This study aimed to predicting the effect of locally available steel fibers on the mechanical properties such as compressive strength, flexural strength and post-peak deformation capability of concrete specimens using fuzzy logic. The simulation was carried-out in fuzzy logic toolbox provided in MATLAB ${ }^{\circledast}$ and its results were compared with the experimental findings. For this purpose, different volumes of steel fibers $0.13 \%, 0.16 \%, 0.24 \%, 0.42 \%$ and $0.84 \%$ $\left(10 \mathrm{~kg} / \mathrm{m}^{3}, 12.5 \mathrm{~kg} / \mathrm{m}^{3}, 15 \mathrm{~kg} / \mathrm{m}^{3}, 17.5 \mathrm{~kg} / \mathrm{m}^{3}\right.$ and $\left.20 \mathrm{~kg} / \mathrm{m}^{3}\right)$ were assimilated in the mix design, and their mechanical properties were determined.

According to simulated results, the addition of steel fibers helped in improving the compressive strength, flexural strength and post-peak deformation capacity of test specimens. The experimental results also supported the findings of fuzzy logic. The compressive strength increased by almost $9.15 \%$, when steel fibers were increased from 0.13 to $0.84 \%$. However, experiments show that the compressive strength of specimens reduced with the addition of steel fibers as compared to specimens without steel fibers (control group).

Both the experimental and simulation results showed an increase in the flexural strength and post-peak deformation capacity of test samples by almost $2 \%$ and $20 \%$ respectively. The reason being, the incorporation of steel fibers bridges the cracked portions of specimens and, enables them to sustain more load before failure.

It is also concluded that fuzzy logic can predict the effect of steel fibers on the mechanical properties of concrete. The difference between the predicted and experimental values is less than $7.5 \%$. The correlation factor ' $\mathrm{R} 2$ ' showed good agreement between the measured and predicted values.

\section{Compliance with ethical standards}

Conflict of interest None.

\section{References}

1. Abbass W, Khan MI, Mourad S (2018) Evaluation of mechanical properties of steel fiber reinforced concrete with different strengths of concrete. Constr Build Mater 168:556-569

2. Fathi H, Lameie T, Maleki M, Yazdani R (2017) Simultaneous effects of fiber and glass on the mechanical properties of selfcompacting concrete. Constr Build Mater 133:443-449

3. Falliano D, De Domenico D, Ricciardi G, Gugliandolo E (2019) Compressive and flexural strength of fiber-reinforced foamed concrete: effect of fiber content, curing conditions and dry density. Constr Build Mater 198:479-493

4. Wu T, Yang X, Wei H, Liu X (2019) Mechanical properties and microstructure of lightweight aggregate concrete with and without fibers. Constr Build Mater 199:526-539

5. Yoo D, Yoon Y (2015) Structural performance of ultra-high-performance concrete beams with different steel fibers. Eng Struct 102:409-423

6. Lee $\mathrm{JH}, \mathrm{Cho} B, \mathrm{Choi} \mathrm{E}$ (2017) Flexural capacity of fiber reinforced concrete with a consideration of concrete strength and fiber content. Constr Build Mater 138:222-231

7. Fallah S, Nematzadeh M (2017) Mechanical properties and durability of high-strength concrete containing macro-polymeric and polypropylene fibers with nano-silica and silica fume. Constr Build Mater 132:170-187 
8. Qin Y, Zhang X, Chai J, Xu Z, Li S (2019) Experimental study of compressive behavior of polypropylene-fiber-reinforced and polypropylene-fiber-fabric-reinforced concrete. Constr Build Mater 194:216-225

9. Yoo DY, Kim S, Park GJ, Park JJ, Kim SW (2017) Effects of fiber shape, aspect ratio, and volume fraction on flexural behavior of ultra-high-performance fiber-reinforced cement composites. Compos Struct 174:375-388

10. Tayfur G, Erdem TK, Kırca Ö (2014) Strength Prediction of highstrength concrete by fuzzy logic and artificial neural networks. J Mater Civil Eng 26(11):1-7. https://doi.org/10.1061/(ASCE) MT.1943-5533.0000985

11. Akkurt S, Tayfur G, Can S (2004) Fuzzy logic model for the prediction of cement compressive strength. Cem Concr Res 34:1429-1433

12. Sarıdemir M (2009) Predicting the compressive strength of mortars containing metakaolin by artificial neural networks and fuzzy logic. Adv Eng Softw 40(9):920-927

13. Topc B (2008) Prediction of compressive strength of concrete containing fly ash using artificial neural networks and fuzzy logic. Comput Mater Sci 41:305-311

14. Thamma P, Barai SV (2009) Prediction of compressive strength of cement using gene expression programming

15. ASTM C 150/C150 M (2017) Standard specification for portland cement. In: ASTM Int

16. ASTM C33/C33 M (2013) Standard specification for concrete aggregates. In: ASTM Int

17. Grzymski F, Musiał M, Trapko T (2019) Mechanical properties of fibre reinforced concrete with recycled fibres. Constr Build Mater 198:323-331

18. de Alencar-Monteiro VM, Lima LR, de Andrade-Silva F (2018) On the mechanical behavior of polypropylene, steel and hybrid fiber reinforced self-consolidating concrete. Constr Build Mater 188:280-291

19. ASTM C39/C39M (2018) Standard test method for compressive strength of cylindrical concrete specimens. In: ASTM Int

20. ASTM C293/C293 M (2016) Standard test method for flexural strength of concrete (using simple beam with center-point loading). In: ASTM

21. Zadeh LA et al (2013) Real-life applications of fuzzy logic. Adv Fuzzy Syst 2013:1-3

22. Muhammad A, Muhammad I, Muhammad W, Muhammad I, Muhammad Imran H, Riaz M (2017) Fuzzy logic approach for investigation of microstructure and mechanical properties of Sn96.5-Ag3.0-Cu0.5 lead free solder alloy. Solder Surf Mt Technol 29(4):191-198

23. Tanyildizi $\mathrm{H}$ (2009) Fuzzy logic model for prediction of mechanical properties of lightweight concrete exposed to high temperature. Mater Des 30(6):2205-2210

24. Pedrycz W (1994) Why triangular membership functions? Fuzzy Sets Syst 64:21-30

25. Haq I, Anwar S, Shah K, Khan MT (2015) Fuzzy logic based edge detection in smooth and noisy clinical images. PLOS ONE 10(9):1-17. https://doi.org/10.1371/journal.pone.0138712

26. Ghasemi M, Ghasemi MR, Mousavi SR (2019) Studying the fracture parameters and size effect of steel fiber-reinforced selfcompacting concrete. Constr Build Mater 201:447-460

Publisher's Note Springer Nature remains neutral with regard to jurisdictional claims in published maps and institutional affiliations. 